\title{
Participation of Adolescent Pupils in Recreational Activities with Greek Dances and Their Preference for Group Work at School
}

\author{
Lemonia Darginidou', Dimitris Goulimaris², Soultana-Anna Toumpalidou' and Filippos Filippou² \\ 'Democritus University of Thrace, Komotini, Greece, ${ }^{2}$ Democritus University of Thrace, Department of Physical Education \& Sport Sciences, Komotini, \\ Greece
}

\begin{abstract}
This paper aimed to study the adolescents' preference from group work at school when participating in recreational activities with Greek dances. The sample of the research consisted of 280 adolescents, aged 12-13, divided into three groups as follows: 97 adolescents who had not dealt with any physical activity systematically, 84 adolescents who had only participated in physical activity programmes with Greek dances organized by secondary schools, and 99 adolescents who had participated in recreational activities with Greek dances organized by non-profit cultural societies. The measurement instrument was the first factor, "preferring group work", from the questionnaire Feelings towards Group. Three measurements took place. For the statistical analysis of the data, the methods used were: analysis of the variance of two factors with one of them being repeated. Consequently, the adolescents' participating in recreational activity programmes with Greek dances contributes to their preference for group work and developing positive feelings about it.
\end{abstract}

Keywords: traditional dance, adolescents, preference for group work

\section{Introduction}

Group and group work

What leads to the establishment of group work is the fact that it constitutes a way of using human energy to make quality decisions and take initiatives for problem-solving. The power of a group is defined by its team spirit and depends on the actions of its members. The ability of a group to achieve its goals is defined by participation. Being flexible, a group can respond to quick changes and demands and adjust to new information and challenges. It can also understand procedures better and thus reduce lost time, improve communication and effectiveness, helping its members to develop their cognitive skills and other characteristics of their personalities (Diaz \& Pintozzi, 1999; Mpourantas \& Papalexandri, 1998). Successful group work is the result of the cooperation and social interdependence of its members, who are willing to contribute to the creation of a positive and effective environment, without individualized competitiveness (Tarricone \& Luca, 2002). Interaction and communication among groups of students improve performance and create qualitative characteristics that aid in the development of knowledge (Joyce \& Weil, 1992; S. Sharan \& C. Shachar, 1988; Slavin, 1987). Freeman (1996) asserted that students' tendency to group work predicts their effective performance.

At school

Education constantly attempts to redefine curricula and use new cognitive strategies, drawing from data that show that

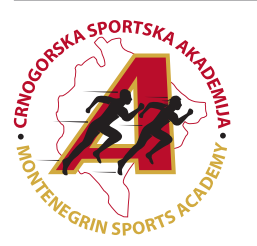

Correspondence: 
group work improves students' social and academic performances (Slavin, 1995). The educational process applies social interaction as a central, fundamental, and thus indispensable element in the cognitive process. It is known that in a sociable environment, students create friendships and inter-personal relationships that help them better understand and apply social skills and join social groups in order to improve their quality of life. For education in Greece, creating a team spirit is a useful strategy since it contributes to the development of a cognitive, social, and moral individual autonomy, as well as to the development of collective practices and attitudes, which should be the objective of a school. As a result, teaching has an intense social-shaping character that reduces antisocial behaviour through obeying given rules. Group/cooperative strategy is applied by creating small groups, planning and organizing, as well as presenting collective activities (Goudas, Hasandra, Papacharisis, \& Gerodimos, 2006; Mountakis, 2006). Greek schools, in general, apply educational programmes and activities with Greek dances, which focus on the interaction between individuals and groups. These programmes are carried out with the voluntary participation of male and female students and supervised by school teachers after the end of the school day (extra-curricular) supporting the school curriculum.

\section{Recreational activities with Greek dances}

Recreational activities with Greek dances are capable of reassuring the suitable cooperative teaching/learning environment, reducing competitiveness, and developing team spirit, which promotes positive social behaviour (Arnold, 1998). Greek dance is a popular activity that, being recognized as recreational, involves adolescents in pleasant activities, combining learning and moving. It is a kind of a group physical and recreational activity that is connected to the quality of life, increasing well-being and reducing anxiety (Mavrovouniotis, Argiriadou, \& Papaioannou, 2010). Participating in recreational activities with Greek dances reinforces socializing and bonding, and creates a pleasant environment of good mood and entertainment, which helps the participants attract more people in their groups (Zanou, Hasandra \& Goudas, 2001). The adolescent participants are motivated to have fun, feel like members of a group and meet with friends, which increases their good mood (Doulias, Kosmidou, Pavlogiannis, \& Patsiaouras, 2005). Participating in such activities creates broader social dimensions, since it is followed by a system of values, such as the collective conscience of a social group, the development of team spirit, and the shaping of the personality of young people. Participants can express themselves both individually and as a group in a collective unity, which reflects the ideological, psychological, and social world of the group (Zografou, 2003). The way these dance programmes function establishes collectivity and solidarity among the participants through the common target of creating a functional dance group, and it is a proof for the existence of social dynamics (Goutsidis, 2004; Maisonneuve, 2001). Dance programmes also constitute social events, and this sociability is expressed throughout the procedure by the whole group/community, regardless of the social or financial status of the participants (Mpougiesi, Zisi, Grigoriou, \& Pollatou, 2011). Within the environment of recreational activities with Greek dances, male and female adolescents are in a constant educational process of social embodiment. Incorporating in a group of recreation- al activities, such as Greek dance programmes, requires communication, cooperation, coordination, and understanding of role distribution. In other words, adolescents must display a high level of social skills in order to be successful.

Adolescents who participate in Greek dance programmes are individually independent, and they simultaneously feel accepted in the groups of their peers, family, and community, which enhances their active participation. The environment of the dance community is perceived as something familiar, an extension of the family, and thus complementary to their education and evolution (Zikos, 1992).

Participation in Greek dance programmes develops young people's motor, observational, and perceptive skills, as well as their concentration, initiative, responsibility, and communication (Mpournelli, 2003). In addition to offering special dance skills, Greek dance uses the body as a tool for action, communication, and creativity (Koutsoumpa, 2007). Therefore, adolescents are given the opportunity to discover rhythm and creative skills, develop their relationships, communicate, and cooperate with their peers, learn and accept group rules, boundaries, and limitations (Likesas, Tsapakidou, Kostantinidou, \& Papadopoulou, 2002). Furthermore, skilled dancers prefer group work at school (Darginidou \& Goulimaris, 2016).

This study aimed to investigate the extent to which adolescents prefer group work at school when they participate in recreational programmes with Greek dances.

\section{Methods \\ Participants}

The participants of the research were 280 adolescents, aged 12-13, who studied in the first year of a junior high school. There were three groups. The "control group" consisted of 97 male and female adolescents, who had not dealt systematically with any extra-curricular physical activity. "Experimental group 1" consisted of 84 male and female adolescents who, for the first time, dealt with extra-curricular activities with Greek dances organized by their school. "Experimental group 2" consisted of 99 male and female adolescents who, for the first time, dealt with extra-curricular activities with Greek dances organized by non-profit cultural societies.

\section{Measurement Instrument}

To evaluate the adolescents' perceptions and emotions towards group work at school, the method used was the questionnaire "Feelings Towards Group" by Cantwell and Andrews (2002), which was adjusted for the Greek language (Magotsiou \& Goudas, 2009) and previously used in research studies in Greece (Filippou \& Kouthouris, 2014; Gousia \& Kouthouris, 2011). The questionnaire consists of 24 questions grouped into three factors. The first factor used was called "preference for group work". It includes eight questions, such as "I like working in groups because in this way we help each other". The specific factor reveals a general preference expressed by adolescents towards group work in class, their satisfaction drawn from the composition and organization of the group they are part of, as well as an intense sense of responsibility and self-knowledge in relation to the role that each one plays in that group.

\section{Procedure}

The completion of the questionnaires took place after the end of the lessons. The participants were told that they could stop the procedure any time they wished, since their partic- 
ipation was voluntary. There were three measurements. The final one ( $2^{\text {nd }}$ measurement) took place seven months after the initial ( $1^{\text {st }}$ measurement), and the preservation measurement ( $3^{\text {rd }}$ measurement) took place two weeks after the $2^{\text {nd }}$ and final measurement. The elaboration of the collected data was carried out with the statistical packet SPSS.18.

\section{Data analysis}

For the statistical analysis of the data, the researchers used elements of descriptive statistics. There was also a reliability analysis for the calculation of a Cronbach and analysis of variance of the two factors, one of which was repeated.

\section{Results}

Estimation of internal cohesion

To estimate the internal cohesion of the examined factor, there were reliability analyses for a Cronbach. Table 1 shows the reliability analyses in the three measurements.

Table 1. Reliability analysis of the factor "Preference for Group Work"

\begin{tabular}{cccc}
\hline & \multicolumn{3}{c}{ a Cronbach } \\
\cline { 2 - 4 } & Measurement 1 & Measurement 2 & Measurement 3 \\
\hline Preference for Group Work & 0.71 & 0.76 & 0.79 \\
\hline
\end{tabular}

\section{Research for differences in the initial measurement}

There was a one-way ANOVA analysis of variance of the independent samples to investigate the differences among the groups in the initial measurement. The analyses showed that there were no statistically significant differences in the factor "Preference for Group Work" in the initial measurement $\mathrm{F}(2,278)=0.411, \mathrm{p}=0.66$ (Table 2$)$.

Analysis of variance of two factors, one of which was repeated for the factor "Preference for Group Work"

To confirm the existence of statistically significant differences in the sample (which was separated according to an independent (group) and a repeated (measurement) factor) concerning the factor "Preference for Group Work", there was an analysis of variance of two factors, with one of them being repeated. It was confirmed that there was a statistically significant interaction between the two factors $\left(\mathrm{F}_{(4,550)}=195.667\right.$, $\mathrm{p}<.05)$. When analysing the interaction for each scale of the independent factor, it was found that there was a statistically significant influence of the repeated factor "measurement" on the "control group" $\left(\mathrm{F}_{(2,278)}=119.472, \mathrm{p}<.05\right)$, the "experimental group 1" $\left(\mathrm{F}_{(2,278)}=52.633, \mathrm{p}<.05\right)$ and the "experimental group 2" $\left(\mathrm{F}_{(2,278)}=105.740, \mathrm{p}<.05\right)$. The Bonferroni multiple comparison test showed that there were statistically significant differences in the "control group" throughout the measurements. It was also found that in "experimental group 1" and "experimental group 2" there were statistically significant differences between the initial and the other two measurements. Following observation of the means (Table 2), it can be confirmed that in the "control group" there was a reduction concerning group work at school throughout the measurements. In "experimental group 1" and the "experimental group 2", there was an increase of the means concerning group work at school, which was kept on the same levels until the end of the measurements, with the "experimental group 2" displaying higher means. In relation to the differentiation among the groups, there were statistically significant differences during the second measurement $\left(\mathrm{F}_{(2,277)}=226.55, \mathrm{p}<.05\right)$ and the third measurement $\left(\mathrm{F}_{(2,277)}=324.127, \mathrm{p}<.05\right)$. The Bonferroni multiple comparison test showed that there were statistically significant differences among the three groups of adolescents. Following the observation of the means (Table 2), during the second and the third measurement, it can be confirmed that the highest means appears in the "experimental group 2".

Table 2. Mean and standard deviations in the measurements for the three groups, during the three measurements

\begin{tabular}{|c|c|c|c|c|c|}
\hline & & $\begin{array}{c}C G \\
M \pm S D\end{array}$ & $\begin{array}{c}\mathrm{EG} 1 \\
\mathrm{M} \pm \mathrm{SD}\end{array}$ & $\begin{array}{c}\mathrm{EG2} \\
\mathrm{M} \pm \mathrm{SD}\end{array}$ & $\begin{array}{c}\text { total } \\
M \pm S D\end{array}$ \\
\hline \multirow{3}{*}{ Preference for Group Work } & Measurement 1 & $3.78 \pm 0.55$ & $3.76 \pm 0.38$ & $3.83 \pm 0.53$ & $3.79 \pm 0.50$ \\
\hline & Measurement 2 & $3.18 \pm 0.54$ & $4.30 \pm 0.35$ & $4.52 \pm 0.48$ & $3.99 \pm 0.76$ \\
\hline & Measurement 3 & $2.98 \pm 0.51$ & $4.30 \pm 0.35$ & $4.53 \pm 0.47$ & $3.93 \pm 0.83$ \\
\hline
\end{tabular}

Legend: CG - control group; EG1 - experimental group 1; EG2 - experimental group 2, M - arithmetic mean; SD - standard deviation

\section{Discussion}

This paper investigated the adolescents' preference for group work at school when they participate in recreational activities with Greek dances. Male and female adolescents prefer to work in groups in class, when they are satisfied by the organization and dynamics of the group to which they belong and when they have developed self-confidence, responsibility, and capability for their role and function in the group (Magotsiou \& Goudas, 2009). There was a general estimation that the adolescents who participated in the research had a very good level of preference towards group work at school, since their means concerning group work fluctuated from 3.79 to 3.99 on a fivescale climax (Table 2).

During the measurements, the groups that participated in recreational programmes with Greek dances differentiated their means of preferences towards group work at school. There was also a differentiation in the means concerning group work at school among the groups, with the highest ones being the means of the group that participated in recreational programmes with Greek dances in societies, as shown in the preservation measurement (Table 2). All groups differentiated their means concerning group work at school, as shown by the results that are in accordance with those of other research studies (Darginidou \& Goulimaris, 2016). It is known that programmes with Greek dances satisfy the participants' needs for individual expression and creation (Dimas, Vagenas, \& Giosos, 2003). Participating in Greek dance programmes requires communication, cooperation, team spirit, coordina- 
tion, and acceptance of the distinction of roles. It seems that the adolescents who participate in recreational activities with Greek dances have learnt to overcome difficulties within the group, communicating, and helping each other. In addition, they discover rhythm, creative skills and they develop or improve relationships, they communicate and cooperate with peers and they learn to obey rules and accept limitations (Likesas, Tsapakidou, Kostantinidou, \& Papadopoulou, 2002).

\section{Acknowledgements}

There are no acknowledgements.

\section{Conflict of Interest}

The authors declare that there are no conflicts of interest.

Received: 16 October 2019 | Accepted: 09 January 2020 | Published: 01 February 2020

\section{References}

Arnold, P. (1998). Sports, Ethics and education. G.B., Cassell.

Cantwell, R.H. \& Andrews, B. (2002). Cognitive and psychological Factors Underlying Secondary Students' feelings Towards Group Work. Educational Psychology, 22, 75-91.

Darginidou, L. \& Goulimaris, D. (2016). Cooperative Learning as a Preference of Adolescent Students: The Case of Dance Activities. Academic Journal of Interdisciplinary Studies, 5(3), S1.

Diaz, J.R. \& Pintozzi, C. (1999). Helping Teams Work: Lessons Learned from the University of Arizona Library Reorganization. Library Administration and Management, 13(1), 27-36.

Dimas, E., Vagenas, G., \& Giosos, J. (2003). The effects of dancing frequency of the parents and the place of residence on the determination of students dancing preferences. Physical Education, Sports, Health 14(15), 15-28.

Doulias. E., Kosmidou, E., Pavlogiannis, O. \& Patsiaouras, A. (2005). Investigate motives for participation by adolescents in traditional dance groups. Inquiries in Physical Education and Sport, 3(2), 107-112.

Filippou, K. \& Kouthouris, X. (2014). The Role of the Camping Participation for the Development of Social Skills. Investigating Differences between Typical Camps and Camps with Outdoor Activity Programs (in Greek). Hellenic Journal of Sport \& RecreationManagement, 11(1), 55-72.

Freeman, K.A. (1996). Attitudes toward work in project groups as predictors of academic performance. Small Group Research, 27, 265-282.

Gossett, M. \& Fisher, O. (2005). Bringing together critical thinking and cooperative earning between two schools. Strategies. Journal of physical and sports educator, 19, 27-30.

Goudas, M., Hasandra, M., Papacharisis, B. \& Gerodimos, B. (2006). Physical education of first grade. Teacher's book. Athens: OEDB.

Gousia, B. \& Kouthouris, X. (2011). Investigation of Primary School Students' Perceptions of Teamwork after Their Participation in an Rural Education Program (In Greek). Hellenic Journal of Sport and Recreation Management, 8(2), 18-28.

Goutsidis, I.D. (2004). Social change and traditional dance. The example of the Monastery. Dancing motley (In Greek). Athens: Ellinika Grammata.
According to the results of this research, recreational programmes with Greek dances that are organized at state schools or non-profit cultural societies seem to help male and female adolescents incorporate themselves into groups and develop a positive attitude towards group work. Consequently, participating in recreational activities with Greek dances contributes to the adolescents' preferring group work and developing positive emotions towards it.

Joyce, B. \& Weil, M. (1992). Models of teaching. Fourth Edition. Englewood Cliffs, NJ: Prentice-Hall.

Koutsoumpa, M. (2007). The teaching of Greek folk dance in contemporary educational contexts. In Folk Culture and Education (In Greek), Proceedings of the 1st International Educational Conference. Cd-rom, ISBN: 978-960-8373-10-5.

Likesas, G., Tsapakidou, A., Kostantinidou, M. \& Papadopoulou, D.S. (2002). New Approaches to theaching traditional Greek dances in elementary education. Journal of Human Movement Studies, 43, 429-442.

Magotsiou, E. \& Goudas, M. (2009). Description and Instructions for Use of the Feelings toward Group Work. Trikala: University of Thessaly. Laboratory of Exercise Psychology and Quality of Life.

Maisonneuve, J. (2001). Introduction to Psychosocial Studies (by N. Christakis). Athens, Typothito-Dardanos.

Mavrovouniotis, F.H., Argiriadou, E.A. \& Papaioannou, Ch.S. (2010). Greek traditional dances and quality of old people's life. Journal of Bodywork \& Movement Therapies, 14, 209-218.

Mountakis, K. (2006). Physical education. Issue of training material. Ministry of Education, Athens: PI.

Mpougiesi, M., Zisi B., Grigoriou, S., \& Pollatou, M. (2011). Greek folk dance, systematic participation affects quality of life in young and middle age adults (In Greek). Inquiries in Sport \& Physical Education, 9(2), 134 - 143.

Mpourantas, D. \& Papalexandri, N. (1998). Introduction to Business Management. Athens, Benos.

Mpournelli, P. (2003) The Creative Dance in Education. Physical EducationSports-Health, 14(15), 43-55.

Sharan, S. \& Shachar, C. (1988). Language and Learning in the cooperative classroom. New York: Springer.

Slavin, R.E. (1987). Cooperative learning. Washington, DC: National Education.

Slavin, R.E. (1995). Cooperative learning: Theory, research, and practice. Harlow, Essex: Allyn \& Bacon.

Tarricone, P. \& Luca, J. (2002). Employees, teamwork and social interdependence- - a formula for successful business? Team Performance Management: An International Journal, 8(3/4), 54-59.

Zanou, S., Hasandra, M., \& Goudas, M. (2001). Investigating the Reasons for Participation in Physical Leisure Activities: A Qualitative Study in People Participating in Traditional Dance Complexes. Sport Psychology, 12, 61-72.

Zikos, G. (1992). The choreological phenomenon of the province of Vojo Kozani: pedagogical significance and educational force of the neo-ellenic dance. Unpublished PhD Thesis, EKPA, TEFAA, Athens, Greece.

Zografou, M.( 2003). Dance in Greek Tradition. Athens, ArtWork. 